University of Nebraska - Lincoln

DigitalCommons@University of Nebraska - Lincoln

Roman L. Hruska U.S. Meat Animal Research

U.S. Department of Agriculture: Agricultural Center Research Service, Lincoln, Nebraska

2011

Determinants of bovine thermal response to heat and solar radiation exposures in a field environment

\author{
Brad Scharf \\ University of Missouri, basb62@mizzou.edu \\ Michael J. Leonard \\ United States Air Force \\ Robert L. Weaber \\ University of Missouri, bweaber@ksu.edu \\ Terry L. Mader \\ University of Nebraska-Lincoln, tmader1@unl.edu \\ G. Leroy Hahn \\ USDA-ARS, hahn@email.marc.usda.gov \\ See next page for additional authors
}

Follow this and additional works at: https://digitalcommons.unl.edu/hruskareports

Scharf, Brad; Leonard, Michael J.; Weaber, Robert L.; Mader, Terry L.; Hahn, G. Leroy; and Spiers, Donald E., "Determinants of bovine thermal response to heat and solar radiation exposures in a field environment" (2011). Roman L. Hruska U.S. Meat Animal Research Center. 210.

https://digitalcommons.unl.edu/hruskareports/210

This Article is brought to you for free and open access by the U.S. Department of Agriculture: Agricultural Research Service, Lincoln, Nebraska at DigitalCommons@University of Nebraska - Lincoln. It has been accepted for inclusion in Roman L. Hruska U.S. Meat Animal Research Center by an authorized administrator of DigitalCommons@University of Nebraska - Lincoln. 


\section{Authors}

Brad Scharf, Michael J. Leonard, Robert L. Weaber, Terry L. Mader, G. Leroy Hahn, and Donald E. Spiers 


\title{
Determinants of bovine thermal response to heat and solar radiation exposures in a field environment
}

\author{
Brad Scharf • Michael J. Leonard • Robert L. Weaber • \\ Terry L. Mader • G. Leroy Hahn • Donald E. Spiers
}

Received: 29 March 2010 /Revised: 22 July 2010 / Accepted: 16 August 2010 /Published online: 26 September 2010

(C) ISB 2010

\begin{abstract}
Continuous exposure of cattle to summer heat in the absence of shade results in significant hyperthermia and impairs growth and general health. Reliable predictors of heat strain are needed to identify this condition. A 12-day study was conducted during a moderate summer heat period using 12 Angus x Simmental (Bos taurus) steers (533 \pm $12 \mathrm{~kg}$ average body weight) to identify animal and ambient determinations of core body temperature $\left(T_{\text {core }}\right)$ and respiration rate $(\mathrm{RR})$ responses to heat stress. Steers were provided standard diet and water ad libitum, and implanted intraperitoneally with telemetric transmitters to monitor $T_{\text {core }}$ hourly. Visual count of flank movement at 0800 and 1500 hours was used for RR. Dataloggers recorded air temperature $\left(T_{\mathrm{a}}\right)$, and black globe temperatures $\left(T_{\mathrm{bg}}\right)$ hourly to assess radiant heat load. Analysis was across four periods and 2 consecutive days averaged within each period. Average $T_{\mathrm{a}}$ and $T_{\mathrm{bg}}$ increased progressively from 21.7 to $30.3^{\circ} \mathrm{C}$ and 25.3 to $34.0^{\circ} \mathrm{C}$, respectively, from the first to fourth periods. A model utilizing a quadratic function of $T_{\mathrm{a}}$
\end{abstract}

B. Scharf $\cdot$ R. L. Weaber $\cdot$ D. E. Spiers $(\bowtie)$

Department of Animal Science, University of Missouri,

920 East Campus Drive,

Columbia, MO, USA

e-mail: basb62@mizzou.edu

M. J. Leonard

US Air Force,

Washington, DC, USA

T. L. Mader

Haskell Agricultural Laboratory, University of Nebraska-Lincoln, 57905866 Road,

Concord, NE 68728-2828, USA

G. L. Hahn

Meat Animal Research Center, USDA-ARS,

PO Box 166, Clay Center, NE 68933-0166, USA explained the most variation in $T_{\text {core }}\left(R^{2}=0.56\right)$. A delay in response from 1 to $3 \mathrm{~h}$ did not significantly improve $R^{2}$ for this relationship. Measurements at 0800 and 1500 hours alone are sufficient to predict heat strain. Daily minimum core body temperature and initial 2 -h rise in $T_{\mathrm{a}}$ were predictors of maximum core temperature and RR. Further studies using continuous monitoring are needed to expand prediction of heat stress impact under different conditions.

Keywords Cattle $\cdot$ Transmitter $\cdot$ Heat $\cdot$ Stress $\cdot$ Model

\section{Introduction}

Cattle throughout the world are repeatedly exposed to heat stress during summer months, and this often occurs in the absence of shade and with direct exposure to solar radiation. The result is a significant loss in productivity and impaired wellbeing (as reviewed by Fuquay 1981; Silanikove 2000; Collier and Zimbelman 2007). Although there have been numerous studies of cattle performance in the field environment over a series of days, they have lacked detailed measurements of thermal status (Yousef 1989). Other studies in controlled laboratory environments have made precise measurements of thermoregulatory effector response to heat stress but only over a period of several hours. Only recently have studies begun to make detailed measurements in the field over a period of time representative of normal exposure during the summer (Lefcourt and Adams 1996; BrownBrandl et al. 2005a; Eigenberg et al. 2005; Mader and Kreikemeier 2006; Gaughan et al. 2008; Arias and Mader 2009). Current measurements include air $\left(T_{\mathrm{a}}\right)$ and black globe $\left(T_{\mathrm{bg}}\right)$ temperatures, temperature humidity index (THI), which combines $T_{\mathrm{a}}$ and percent relative humidity (\%RH), and the modified Black Globe Temperature Humidity Index 
(BGTHI), which utilizes $T_{\mathrm{bg}}$ in place of $T_{\mathrm{a}}$. The purpose of this study was to identify the best predictors of heat strain by use of core body temperature ( $T_{\text {core }}$ ) as a response to ambient conditions. By continuously monitoring $T_{\text {core }}$ and ambient conditions, comparisons can made between ambient conditions $\left(T_{\mathrm{a}}, T_{\mathrm{bg}}\right.$, and \%RH) and the generated indices (THI and BGTHI) to determine the best predictors of thermal status.

The primary objective of this study was to utilize ambient and animal indicators of thermal stress and strain, respectively, to better predict the heat stress responses of unshaded and undisturbed feedlot cattle. This objective was realized by a series of steps that determined (1) the relationships between individual ambient variables and animal thermal status, (2) the delayed animal response to thermal stress, (3) the minimal set of observations required (data collection strategy) to identify peak daily thermal strain, and (4) the best combination of these determinants, using stepwise regression analysis, to predict thermal status in a heat challenging environment.

\section{Materials and methods}

Animals

Twelve Angus $\times$ Simmental steers $(533 \pm 12.26 \mathrm{~kg})$ were obtained from the University of Missouri Beef Research Farm. All were previously exposed to heat challenge conditions in the summer field environment and considered to be heat-adapted to early July conditions associated with mid-Missouri. Animals were divided randomly into two unshaded feedlot pens (six steers per pen) for 15 days, with a typical feedlot finishing diet (Table 1; provided once daily midmorning) and water available. Both were provided ad libitum. Feedlot pens were identical in size $(8 \times 18 \mathrm{~m})$ and located adjacent to each other. The experimental and surgical protocol \#3160 was approved by the University of Missouri Animal Care and Use Committee.

\section{Procedure}

Data loggers (Hobo H8 Pro; Onset Computer, Bourne, MA; accuracy: $\pm 0.2^{\circ} \mathrm{C}$ and $\pm 3 \% \mathrm{RH}$ ) were used to record $T_{\mathrm{a}}$ and $\% \mathrm{RH}$, together with $T_{\mathrm{bg}}$ (hollow copper sphere; $15.24 \mathrm{~cm}$ diameter; flat black exterior; Bond and Kelly 1955; located within animal pens) for assessment of radiant heat load. Both THI (Thom 1959; THI $=t_{\text {dry bulb }}+0.36 t_{\text {dewpoint }}+41.2$ ) and BGTHI (Buffington et al. 1981; BGTHI $=t_{\text {black globe }}+$ $0.36 \mathrm{t}_{\text {dewpoint }}+41.2$ ) indices were calculated using these recorded ambient values. Determinations of respiration rate (RR) were made by counting flank movement over a 1-min interval twice a day (i.e., 0800 and 1500 hours). These points
Table 1 Diet for steers used in the feedlot study. All values are in kilograms. NEg Mcal $/ \mathrm{kg}, 0.28$; crude protein, \% 14

\begin{tabular}{lll}
\hline Ingredient & Amount & Percentage \\
\hline Corn & 737.27 & 81.08 \\
Cotton seed hulls & 84.09 & 9.25 \\
Alfalfa meal & 8.77 & 0.96 \\
48\% soybean meal & 11.36 & 1.25 \\
Urea & 9.55 & 1.05 \\
Limestone & 7.73 & 0.85 \\
RTM & 1.36 & 0.15 \\
Vitamins A, D, \& E & 0.32 & 0.04 \\
Purex Salt & 7.73 & 0.85 \\
Molasses & 25.45 & 2.80 \\
Fat & 15.45 & 1.70 \\
Rumensin 80 & 0.11 & 0.01 \\
Tylan 40 & 0.09 & 0.01 \\
\hline
\end{tabular}

were selected prior to data collection for the experiment for measurement of respiration rate because they represent both low and high points of the daily $T_{\text {core }}$ cycle based on preliminary data from our laboratory. Core body temperature was recorded continuously for each animal using a calibrated, telemetric, temperature transmitter (CowTemp Model BV-010; Innotek, Garrett, IN) inserted into the peritoneal cavity approximately 9 weeks prior to start of the study. CowTemp transmitters were factory calibrated $\left(0.05^{\circ} \mathrm{C}\right.$ resolution; $0.3^{\circ} \mathrm{C}$ accuracy), and accuracy verified in the laboratory using an NIST (National Institute of Standards and Technology) thermometer before and after implantation.

For implantation, each animal was restrained standing in stocks with a head gate. The left flank was clipped and surgically scrubbed with a betadine/alcohol preparation. The temperature transmitters were stored in Zepharin chloride for a minimum of $2 \mathrm{~h}$ prior to implantation. A celiotomy was performed with a $20 \mathrm{~cm}$ vertical incision in the left flank skin and musculature where the temperature transmitter was inserted (diameter $4 \mathrm{~cm}$; length $7 \mathrm{~cm}$ ). Sterile, nonabsorbing suture was used to attach the transmitter to the ventral body wall. The muscle layers were then closed with \#3 cat-gut and the skin incision sutured with vetafil. Flunixin meglumine (Banamine) was administered at the end of surgery and repeated doses were given if animals appeared to be in discomfort. Penicillin was given for 3 days post surgery and skin sutures were removed after 10 days.

\section{Experimental design}

The entire study covered a 12-day period of active data collection. Data collection and analysis did not begin until day 2 (Fig. 1) to coincide with a stable $T_{\mathrm{a}}$ range that 
represented a baseline, thermoneutral period for this time of year (i.e., midsummer). Ambient temperature progressively increased over the following 10 days to peak on days 1314. For analyses, animal and temperature data were reduced to hourly averages for each day. Four periods of 2 consecutive days were then assigned to the data set to represent the transition from thermoneutral to heat stress conditions. Each animal's hourly data for these days was averaged, reducing the number of data points for a single animal from 48 to 24 . This process was used to minimize potential variance by homogenizing days within a period, and to limit transmitter artifacts associated with particular animals. Another day separated each period to serve as an assigned "barrier" between two data sets. These days were not used in any analyses of response. Animals were also ranked individually based on minimum and maximum $T_{\text {core }}$ to look at animal variation.

\section{Statistical analysis}

The effects of period on ambient variables $\left(T_{\mathrm{a}}, T_{\mathrm{bg}}, \% \mathrm{RH}, \mathrm{THI}\right.$, and BGTHI) were modeled using the repeated measures ANOVA procedures of JMP ${ }^{\circledR}$ (SAS Institute; Cary, NC) with the ambient variable modeled as the dependent variable, with period, time of day, and period by time of day interaction as independent variables that were modeled as fixed effects. In this set of models and all subsequent ANOVA analyses described below, experiment-wise Type I error rate was controlled to $\alpha=0.05$ utilizing the Tukey HSD adjustment procedures for multiple mean comparisons.

A repeated measures ANOVA, constructed using JMP ${ }^{\circledR}$ (SAS Institute, Cary, NC), was also used to test the effects of period on $T_{\text {core }}$. The model included $T_{\text {core }}$ as the dependent variable, with the independent variables hour

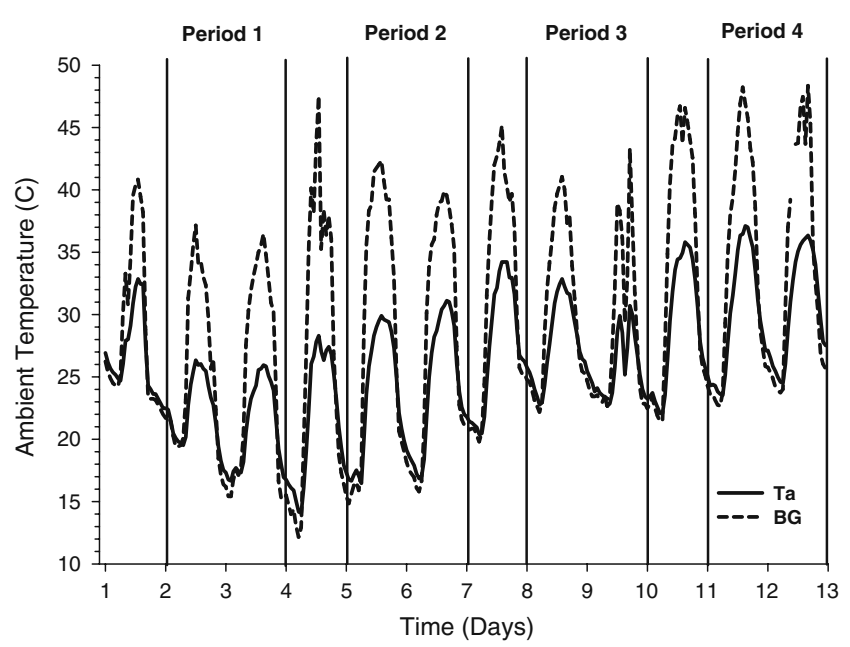

Fig. 1 Hourly air temperature $\left(T_{\mathrm{a}}\right)$ and black globe temperature (BG) in the outdoor, unshaded environment. Solid vertical lines designate the 4 periods used for analysis and period fit as fixed effects, and animal within-period and period-by-hour interaction as random effects. Animal was considered the experimental unit.

Respiration rate, $T_{\text {core }}$ and $T_{\mathrm{a}}$ observations were averaged for each of the 2 days within-period observed at 0800 hours (starting) and 1500 hours (ending). These means were tested by way of ANOVA using JMP ${ }^{\circledR}$ to determine if any statistical differences existed. Of particular interest was the evaluation of starting and ending values of $T_{\text {core }}$ across period. Additionally, within-period differences between observations at 0800 and 1500 hours were tested.

Simple linear regression procedures of $\mathrm{JMP}^{\circledR}$ were utilized to establish the linear relationships between $T_{\mathrm{a}}$ and time of day during the initial rise between 0600 and 0800 hours for each period (Table 3). Regression coefficients (slope) for time, and model $R^{2}$ are reported, as well as $P$ values for the hypothesis test that the time regression coefficients are significantly different from zero. Similarly, simple linear regression was utilized to establish the linear relationships between $T_{\mathrm{bg}}$ and time of day during the initial rise between 0600 and 0800 hours for each period with slope, $R^{2}$ and $P$ values reported.

Quadratic regression models were constructed using $\mathrm{JMP}^{\circledR}$ with a time delay of $0,1,2$, and $3 \mathrm{~h}$ for response variable, $T_{\text {core }}$, to explore the relationships with ambient conditions (Table 4). The data was partitioned into three sets that included $T_{\text {core }}$ and ambient variable pairs for all hours of the day, observations from 0700 to 1800 hours, and observations at 0800 and 1500 hours. These models were designed to determine which combination of delay in response, ambient condition, and data collection strategy best describes changes in $T_{\text {core }}$. Model $R^{2}$ values are reported and were used in the determination of model sufficiency.

Models relating maximum values for RR and $T_{\text {core }}$ to animal and ambient variables were constructed by multiple regression analysis using the all-subsets selection method of model building included in the regression procedures of SAS statistical software (SAS Institute). Mallows $\mathrm{C} p$ criterion (Mallows 1973) was used for selection of the best subset of variables (Bayarri et al. 2003). Animal values were selected using the average of 2 days for each animal and hour within each period. Environmental values for each period were determined across all hours of the day using the average of both days within each period for $T_{\text {core }}$ and the average of both days at 0800 and 1500 for RR. The comparisons with the highest $R^{2}$ and lowest $\mathrm{C} p$ criterion were selected as the best fit relationship.

\section{Results}

Average daily $T_{\mathrm{a}}$ for each period progressively increased over time (Fig. $1 ; P \leq 0.0001$ ) from Period 1 to 4 , with each 
period being significantly greater than the previous. In the case of $T_{\mathrm{a}}$, THI, and BGTHI, the increase was significant $(\alpha=0.05)$ as periods progressed from first to last with the fourth period being always higher than the preceding periods (Table 2). Air temperature exhibited a progressive increase across the four periods of study (Fig. 1; Table 2). On average across all days in the study, $T_{\mathrm{bg}}$ temperature increased to be above $T_{\mathrm{a}}$ at 0700 and decreased to be below $T_{\mathrm{a}}$ at 2100 hours (Fig. 1). Black globe temperature was greater than $T_{\mathrm{a}}$ for $58 \%$ of the day with an average temperature difference of $7.3^{\circ} \mathrm{C}$.

The average daily change in $T_{\mathrm{a}}$ for each period as a function of hour of day is shown in Fig. 2. A summary of the four periods provided the pattern for the daily change in $T_{\mathrm{a}}$. The lowest $T_{\mathrm{a}}$ occurred at $0500-0600$ hours $\left(20.7^{\circ} \mathrm{C}\right)$ with significant increases $(\alpha=0.05)$ to 1000 hours $\left(27.4^{\circ} \mathrm{C}\right)$ and then $1300-1400$ hours $\left(30.7^{\circ} \mathrm{C}\right)$. After 1400 hours, there were significant $T_{\mathrm{a}}$ reductions $(\alpha=0.05)$ to $2000\left(26.5^{\circ} \mathrm{C}\right)$ and then to 2200 hours $\left(23.3^{\circ} \mathrm{C}\right)$. Black globe temperature was below $T_{\mathrm{a}}$ at $0500-0600\left(20.3^{\circ} \mathrm{C}\right.$; Fig. 1), as a result of increased radiant heat loss to the night sky. In fact, $T_{\mathrm{bg}}$ averaged $1^{\circ} \mathrm{C}$ lower than $T_{\mathrm{a}}$ from 2200 to 0200 hours throughout the test period. Solar heating resulted in an increase in $T_{\mathrm{bg}}$ after 0600 hours, which was more rapid than the increase for $T_{\mathrm{a}}$, with $T_{\mathrm{bg}}$ averaging $9.8^{\circ} \mathrm{C}$ above $T_{\mathrm{a}}$ from 1200 to 1400 hours (Fig. 1). Daily peak values in $T_{\mathrm{a}}$ and $T_{\mathrm{bg}}$ were at 1400 hours, with rapid reductions after this time. The THI and BGTHI values paralleled changes in $T_{\mathrm{a}}$ and $T_{\mathrm{bg}}$, respectively, throughout the day. Because of the close relationships between $T_{\mathrm{a}}$ and other ambient variables, all additional analyses of ambient thermal stress across periods concentrated on $T_{\mathrm{a}}$.

An examination of daily $T_{\mathrm{a}}$ changes across period in the present study showed some similarities and differences. The maximum $T_{\mathrm{a}}$ within each period allowed them to be ranked in three groups (Fig. 2; Group \#1: Period 1; Group \#2: Periods 2 and 3; Group \#3: Period 4). In contrast, the minimum point in each period provided an easy separation into two groups (Fig. 2; Group \#1: Periods 1 and 2; Group \#2: Periods 3 and 4). Within the low point periods, there

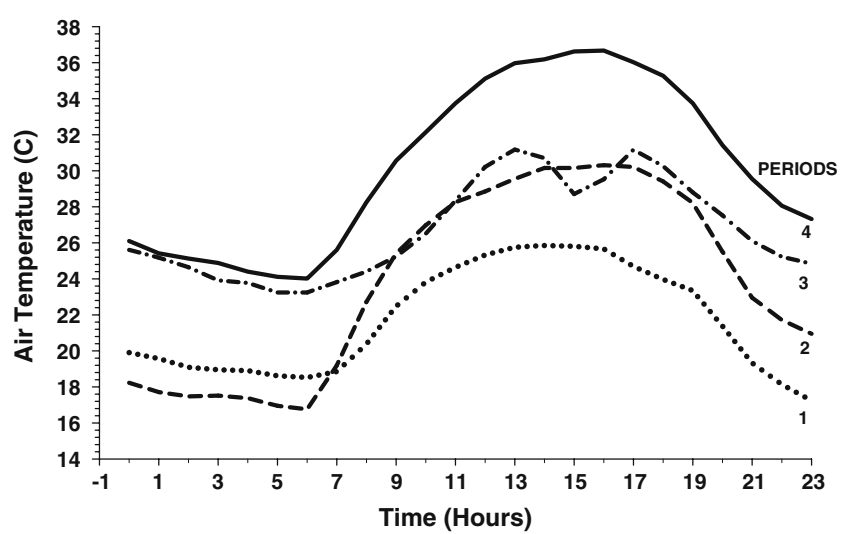

Fig. 2 Air temperature averaged over the 2 days of each period and plotted as a function of hour of day for each period

were differences in the rate of rise (degrees Celsius per hour) in $T_{\mathrm{a}}$ from the 0600 hours point (Table 3 ). The rate of rise in $T_{\mathrm{a}}$ and $T_{\mathrm{bg}}$ from 0600 to 0800 hours was significant $(P<0.01)$ for Periods 2 and 4, even though they had different low and high starting points, respectively. The rates of rise for Periods 2 and 4 were similar, and 2- to 3-fold greater than for the other periods. This information was used in predicting the daily change in $T_{\text {core }}$.

Daily change in $T_{\text {core }}$ in the present study followed $T_{\mathrm{a}}$, with the lowest daily $T_{\text {core }}$, using an average of the periods, occurring at $0700-0800$ hours $\left(37.9^{\circ} \mathrm{C}\right)$ followed by a rapid, significant increase $(P<0.05)$ to 0900 hours $\left(38.2^{\circ} \mathrm{C}\right)$. Hourly increases $(\alpha=0.05)$ occurred after this time to 1300 hours $\left(38.9^{\circ} \mathrm{C}\right)$. Peak $T_{\text {core }}$ was at 1700 hours $\left(39.1^{\circ} \mathrm{C}\right)$, with a significant reduction $(P<0.05)$ by 1900 hours $\left(38.9^{\circ} \mathrm{C}\right)$.

An analysis of $T_{\text {core }}$ across periods in the present study showed no significant differences $(\alpha<0.05)$ until 1100 hours (Fig. 3a). This difference remained in effect through 2000 hours and was associated with Period 4, which was more than $0.5^{\circ} \mathrm{C}$ above that of the other periods. At no time were the average hourly $T_{\text {core }}$ values for the remaining periods significantly different from each other $(\mathrm{P}<0.05)$. Even though Periods 3 and 4 had similar low $T_{\mathrm{a}}$ at the start of the day (Fig. 2) and Periods 2 and 4 had a similar rate of
Table 2 Daily averaged ambient values derived from measurements for the four periods used in the present study. Values within each period were determined using the averages of the 2 days for each period. Values within a row having different superscript letters differ at $\alpha=$ 0.05. DP Dewpoint temperature

\begin{tabular}{lllll}
\hline & \multicolumn{4}{c}{ Periods } \\
\cline { 2 - 5 } Ambient Values & 1 & 2 & 3 & 4 \\
\cline { 2 - 5 } & Mean $\pm \mathrm{SD}$ & Mean $\pm \mathrm{SD}$ & Mean $\pm \mathrm{SD}$ & Mean $\pm \mathrm{SD}$ \\
\hline$T_{\mathrm{a}\left({ }^{\circ} \mathrm{C}\right)}$ & $21.67 \pm 3.00 \mathrm{a}$ & $23.86 \pm 5.23 \mathrm{~b}$ & $26.76 \pm 2.72 \mathrm{c}$ & $30.26 \pm 4.70 \mathrm{~d}$ \\
$\mathrm{BG}\left({ }^{\circ} \mathrm{C}\right)$ & $25.31 \pm 7.36 \mathrm{a}$ & $28.52 \pm 10.11 \mathrm{~b}$ & $29.59 \pm 6.21 \mathrm{~b}$ & $33.97 \pm 9.11 \mathrm{c}$ \\
DP $\left({ }^{\circ} \mathrm{C}\right)$ & $15.43 \pm 1.41 \mathrm{a}$ & $16.01 \pm 0.90 \mathrm{a}$ & $22.23 \pm 0.58 \mathrm{~b}$ & $22.80 \pm 0.79 \mathrm{~b}$ \\
$\%$ RH & $68.27 \pm 16.33 \mathrm{a}$ & $63.25 \pm 18.65 \mathrm{~b}$ & $76.88 \pm 10.39 \mathrm{c}$ & $66.53 \pm 17.70 \mathrm{ab}$ \\
$\mathrm{THI}$ & $68.43 \pm 2.77 \mathrm{a}$ & $70.82 \pm 5.31 \mathrm{~b}$ & $75.96 \pm 2.84 \mathrm{c}$ & $79.67 \pm 4.65 \mathrm{~d}$ \\
$\mathrm{BGTHI}$ & $72.06 \pm 7.08 \mathrm{a}$ & $75.49 \pm 10.13 \mathrm{~b}$ & $78.79 \pm 6.29 \mathrm{c}$ & $83.38 \pm 9.07 \mathrm{~d}$ \\
\hline
\end{tabular}


Table 3 Linear characteristics of initial change $\mathrm{e}^{\mathrm{a}}$ in ambient temperature for each period

\begin{tabular}{|c|c|c|c|c|c|c|}
\hline \multirow[b]{2}{*}{ Period } & \multicolumn{3}{|c|}{ Air temperature } & \multicolumn{3}{|c|}{ Black globe temperature } \\
\hline & Slope $\left({ }^{\circ} \mathrm{C} / \mathrm{h}\right)$ & $R^{2}$ & $P$ Value & Slope $\left({ }^{\circ} \mathrm{C} / \mathrm{h}\right)$ & $R^{2}$ & $P$ Value \\
\hline 1 & 0.93 & 0.45 & 0.15 & 3.36 & 0.75 & 0.03 \\
\hline 2 & 2.98 & 0.91 & 0.01 & 7.82 & 0.84 & 0.01 \\
\hline 3 & 0.58 & 0.17 & 0.42 & 2.34 & 0.30 & 0.26 \\
\hline 4 & 2.12 & 0.91 & 0.01 & 5.98 & 0.98 & 0.01 \\
\hline
\end{tabular}

${ }^{\mathrm{a}} 0600$ to 0800 hours

magnitude of the total daily increase in this variable, and both differences and similarities noted previously across the four periods. We were especially interested in the time frame of rapid increase in $T_{\mathrm{a}}$ from 0600 to 1200 hours (Fig. 2). Interestingly, the time frame for the most rapid increase $(\alpha=0.05)$ in $T_{\text {core }}$ for all periods was 0500 to 1200 hours (Fig. 3b). The low point for upward change in $T_{\text {core }}$ during the day was 1200 to 1500 hours, with the greatest decrease from 1500 to 2200 hours. The differences in the 2-h rate of change in $T_{\text {core }}$ across period provided some explanation for the absolute differences in $T_{\text {core }}$ across periods. Period 4 values for the 2 -h increase were highest $(\alpha=0.05)$ for all periods and times from 0600 to 1100 hours (i.e., 0.7 to $0.8^{\circ} \mathrm{C} / 2-\mathrm{h}$ ). The values for Period 4 were significantly higher $(P<0.05)$ than for most of the other periods from 0400-0600 through 1800-2000 hours. The largest negative rate of change in $T_{\text {core }}$ was from 1500 to 2100 hours (i.e., -0.4 to -0.6 ) for Period 4 . These large differences in the rate of change in $T_{\text {core }}$ during early and late times of the day might explain the significantly larger increase in $T_{\text {core }}$ during this period $(P<0.05)$.

The rate of change in $T_{\text {core }}$ response to heat stress is important as a determinant of the daily magnitude of heat strain. However, there are additional considerations of the relationships between $T_{\text {core }}$ and ambient variables. The two ambient measurements in the present study (i.e., $T_{\mathrm{a}}$ and $T_{\mathrm{bg}}$ ) are presented in Fig. 4 as predictors of $T_{\text {core }}$. Quadratic relationships were generated for both variables using 24$\mathrm{h}$ averages for each animal for each period (i.e., $n=1,148$ ). The equations for $T_{\mathrm{a}}$ and $T_{\mathrm{bg}}$ were $T_{\text {core }}=42.3102-0.3808$ $T_{\mathrm{a}}+0.0088 T_{\mathrm{a}}^{2}$ (Adjusted $\left.R^{2}=0.55 ; P<0.0001\right)$ and $T_{\text {core }}=$ $40.1815-0.1590 T_{\mathrm{bg}}+0.0033 T_{\mathrm{bg}}^{2}$ (Adjusted $R^{2}=0.37$; $P<0.0001)$, respectively. Each coefficient in these equations was significant at $P<0.0001$. It can be seen in Fig. 4 that $T_{\mathrm{a}}$ and $T_{\mathrm{bg}}$ relationships with $T_{\text {core }}$ overlap from approximately 16 to $25^{\circ} \mathrm{C}$ to explain the night-time overlap seen in Fig. 1. Air temperature is the better predictor of $T_{\text {core, }}$ therefore, additional details were evaluated to show the contribution of each period to the relationship. It can be clearly seen that Period 4 was the primary contributor to the quadratic relationship presented in Fig. 4. Although mean $T_{\mathrm{a}}$ increased more than $5^{\circ} \mathrm{C}$ from Periods 1 to 3 , it was the $3.5^{\circ} \mathrm{C}$ increase from Period 3 to 4 that defined this relationship.
Fig. 3 A Core body temperature is shown as a function of time of day for each of the four test periods. Change in core body temperature over the previous $2 \mathrm{~h}$ is shown in $\mathbf{B}$ as a function of time of day. Values used were hourly averages for each animal across the 4 days in each period 
Table 4 presents the $R^{2}$ values for the quadratic relationships between $T_{\text {core }}$ and $T_{\mathrm{a}}, T_{\mathrm{bg}}$, THI, and BGTHI to determine which is the more reliable predictor for $T_{\text {core }}$. With no delay between the $T_{\text {core }}$ response and ambient stressor, it is seen that $T_{\mathrm{a}}$ is the better predictor. To determine if such a delay would improve the quadratic relationship with $T_{\text {core }}$, delays of 1,2 , and $3 \mathrm{~h}$ were evaluated (Table 4). Many of the delays increased the $R^{2}$ value above the zero delay level. However, the maximum increase in $R^{2}$ from the use of $T_{\mathrm{a}}$ with zero delay (i.e., 0.56 ) was only 0.04 for a 1 -h delay. This was not a large enough increase to warrant building a delay component into further evaluations.

The objective presented in Fig. 5a was to compare different segments of the daily $T_{\text {core }}$ relationship to $T_{\mathrm{a}}$, using animals in the four periods of the present study to determine which best predicts the quadratic relationship shown in Fig. 4. The Fig. 4 expression is shown as "All Hours", with hours for both days in each period averaged for each animal. In addition, the $95 \%$ confidence interval is shown. The data from 0700 to 1600 hours are plotted to represent the daily period when there is the largest increase in $T_{\text {core. }}$ The inset in Fig. 5 presents the average for all animals and all periods across hours of the day. A significant increase in $T_{\text {core }}$ occurred $(P<0.05)$ from 0600 $0800\left(37.93-8.03^{\circ} \mathrm{C}\right)$ to $1400-1800$ hours $\left(39.02-39.13^{\circ} \mathrm{C}\right)$. Therefore, inclusion of data from 0700 to 1600 hours is within this period of increase. The quadratic equation for this relationship was $T_{\text {core }}=42.9219-0.4440 T_{\mathrm{a}}+0.0101 T_{\mathrm{a}}^{2}$ (adjusted $R^{2}=0.69 ; P \leq 0.05$ ). It is noted that the $T_{\mathrm{a}}$ range for the largest increase in $T_{\text {core }}$ (i.e., 30 to $37^{\circ} \mathrm{C}$ ) overlaps with the $95 \%$ confidence interval for the relationship using all hours of the day. It was expected that the $R^{2}$ value would

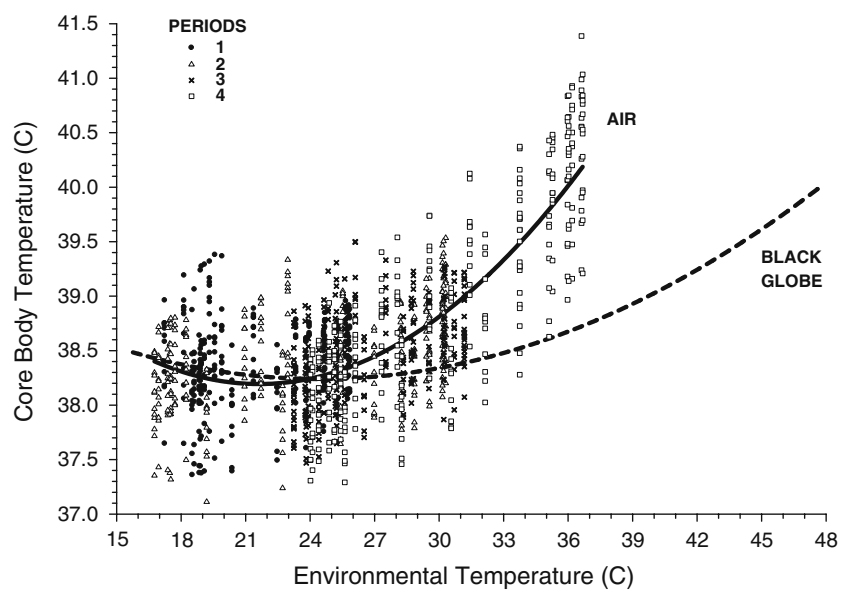

Fig. 4 The quadratic relationships of core body temperature to air and black globe temperatures is shown using each of the four periods. Values used in the calculations were hourly averages for each animal across the 4 days in each period. Only points for the air temperature relationship are displayed to illustrate the variance around each fitted line increase with the use of fewer points in the calculation. The third quadratic expression used only for $T_{\text {core }}$ values at 0800 and 1500 hours. It can be seen that they fall within the previously noted low and high daily $T_{\text {core }}$ ranges of 0600 0800 and $1400-1800$ hours (Fig. 5, inset), respectively. The quadratic equation for this relationship is $T_{\text {core }}=43.0706-$ $0.4687 T_{\mathrm{a}}+0.0108 T_{\mathrm{a}}^{2}$ (adjusted $R^{2}=0.74 ; P \leq 0.05$ ). Once again the adjusted $R^{2}$ increases due to an even greater reduction in sample size, and there is overlap during heat stress between this expression and the one that uses all hours of the day.

The relationship between $T_{\text {core }}$ and $T_{\mathrm{a}}$ was further analyzed using a delay in $T_{\text {core }}$ response (Table 4) for $T_{\mathrm{a}}$, $T_{\mathrm{bg}}$, THI, and BGTHI, but considering the $T_{\text {core }}$ values from 0700 to 1600 and at only 0800 and 1500 hours. The results are presented in the table within Fig. 5, which shows the adjusted $R^{2}$. The largest increase in this value was with a 1$\mathrm{h}$ delay. However, the magnitude of this increase was only 0.02 . Respiration rates were only collected at 0800 and 1500 hours in the present study as representatives of daily low and high values, respectively. Figure 6 shows the average RR for these hours in each period together with $T_{\text {core }}$ and $T_{\mathrm{a}}$ graphs. Both variables increased significantly from 0800 to 1500 hours in each period, with the fourth period displaying the higher level of heat stress $(P<0.05)$. For the most part, both variables demonstrated the impact of heat stress on the thermal status of the animals. However, RR was able to express the higher heat load at 0800 hours in Period 4, which was not seen for $T_{\text {core }}$.

One goal of the present study was to identify the animal and/or ambient determinants of the thermal stress response in cattle. It has been shown in this study that there are important single ambient predictors, such as $T_{\mathrm{a}}$ and $T_{\mathrm{bg}}$. In addition, the rate of change in $T_{\mathrm{a}}$ from 0600 to 0800 hours, along with the daily low $T_{\mathrm{a}}$, can identify which animals will experience a level of hyperthermia that is above the normal level. Table 5 shows the nine animal and ambient variables used to predict maximum daily RR, using four and five period comparisons. Use of combinations above or below the four to five grouping did not increase $R^{2}$ and reduce the $\mathrm{C} p$ value to warrant inclusion in the final analysis. In fact, the use of five point comparisons, as seen in Table 5, increased $R^{2}$ by only 0.01 and raised the $\mathrm{C} p$ value. The only variable that was a part of all the comparisons was minimum $T_{\text {core }}$, indicating its significance in contributing to the maximum daily RR. Interestingly, neither maximum $T_{\text {core }}$ nor minimum RR were needed in any of the top comparisons using four variables. The slopes of both $T_{\mathrm{a}}$ and $T_{\mathrm{bg}}$ increase from 0600 to 0800 hours were next in importance as indicated by their inclusion in four of the top comparisons. It appeared that either of the remaining variables (i.e., minimum $T_{\mathrm{a}}$ and $T_{\mathrm{bg}}$, maximum $T_{\mathrm{a}}$ and $T_{\mathrm{bg}}$ ) could be used with the slope values and minimum $T_{\text {core }}$ for 


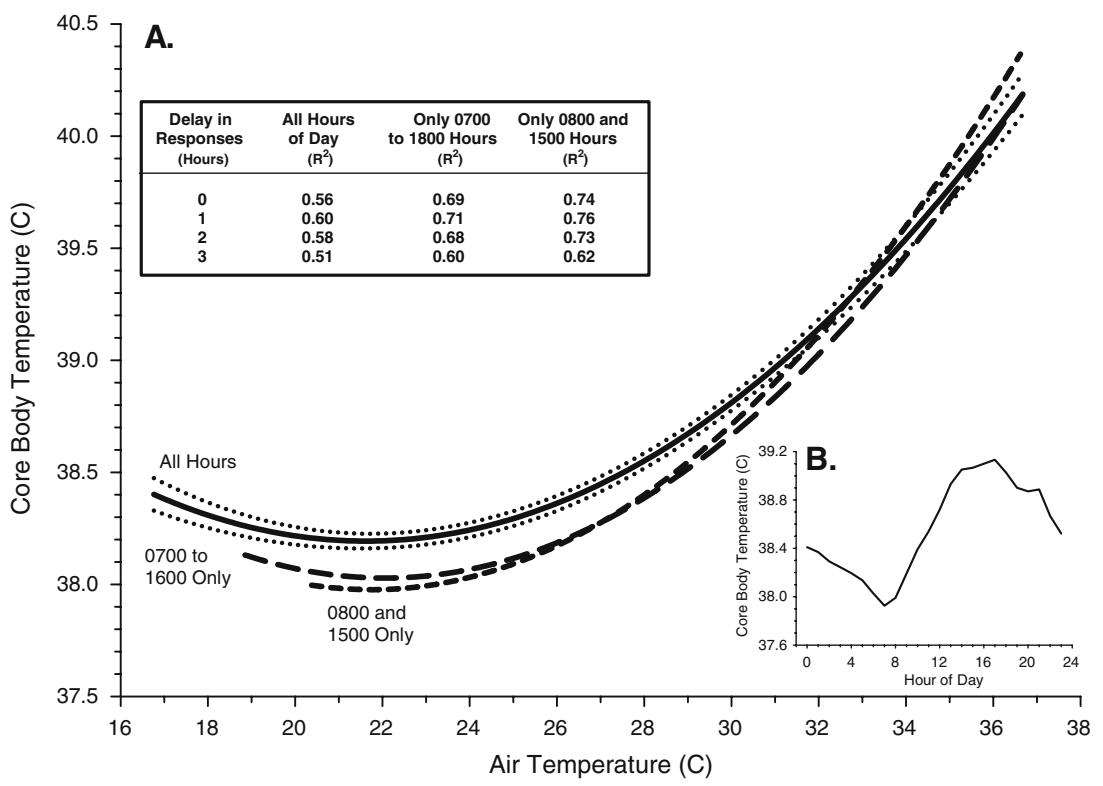

Fig. 5 Comparison of different quadratic expressions of core body temperature as a function of air temperature to determine the minimum number of daily points (main figure) and the maximum hour delay for core body temperature response (Inset $A$ ) was required to best determine heat strain. The relationship using all hours of the day shows the fitted $95 \%$ confidence interval as a dotted line. Inset $B$ Averaged hourly core body temperature across periods for the average

equal effectiveness. Comparison \#5 did not require either $T_{\mathrm{a}}$ or $T_{\mathrm{bg}}$ slopes, but did use maximum and minimum $T_{\mathrm{bg}}$ values. This would serve a similar purpose as the early morning slope values to incorporate a component of the daily change in the environment into the analysis.

Table 6 presents the statistical analyses to predict maximum $T_{\text {core }}$, which is the traditional indicator of heat strain, using daily animal and ambient variables. The variables used in this evaluation were similar to those used for predicting maximum RR (Table 5). Once again, the five component comparison did not provide a significant improvement over the use of four variables, with an increase in $R^{2}$ of only 0.01 and a large increase in $\mathrm{C} p$. In only one of the four variable comparisons (\#6) were RR values important in predicting maximum $T_{\text {core }}$, but this was of each animal within each period. This shows that the increase from 0700 to 1600 hours represented the period of greatest increase in core body temperature, and that 0800 and 1500 hours represented the low and high points, respectively, in core body temperature throughout the study. The inserted table presents the $R^{2}$ values for each of the three relationships with $0-3 \mathrm{~h}$ delays in core body temperature response

not considered because it resulted in a large increase in $\mathrm{C} p$. Unlike the usefulness of minimum $T_{\text {core }}$ to predict maximum RR, the reverse was not true for RR prediction of maximum $T_{\text {core }}$; however, limited sampling of only 0800 and 1500 hours were used.

Minimum $T_{\text {core }}$ was still the common factor in all the top statistical analyses to predict maximum $T_{\text {core }}$. Another similarity with the prediction of maximum $R R$ was the incorporation of 0600 to 0800 slopes for $T_{\mathrm{a}}$ and $T_{\mathrm{bg}}$ into all of the top five predictions for maximum $T_{\text {core. }}$. The benefit of the $T_{\mathrm{a}}$ slope in the model is illustrated by comparisons \#1 and 5 (Table 6) where removal of the slope value results in a decrease in $R^{2}$ from 0.85 to 0.71 , and a 10 -fold increase in $\mathrm{C} p$. As for the prediction of maximum RR, any of the four remaining variables could be used in the statistical analysis

Table $4 R^{2}$ values for core temperature quadratic relationship to ambient conditions using 0,1 , 2, and 3-h delays in animal response ${ }^{\mathrm{a}, \mathrm{b}, \mathrm{c}}$

\begin{tabular}{lllll}
\hline $\begin{array}{l}\text { Delay in response } \\
\text { (hours) }\end{array}$ & $\begin{array}{l}\text { Air } \\
\text { temperature }\end{array}$ & $\begin{array}{l}\text { Black globe } \\
\text { temperature }\end{array}$ & $\begin{array}{l}\text { Temperature humidity } \\
\text { index }\end{array}$ & $\begin{array}{l}\text { Black globe temperature humidity } \\
\text { index }\end{array}$ \\
\hline 0 & 0.56 & 0.38 & 0.52 & 0.40 \\
1 & 0.60 & 0.47 & 0.57 & 0.50 \\
2 & 0.58 & 0.52 & 0.55 & 0.56 \\
3 & 0.51 & 0.52 & 0.50 & 0.55 \\
\hline
\end{tabular}

${ }^{a}$ Average of both days within a period were used for each animal in an analysis

${ }^{\mathrm{b}}$ Each animal was used in the analysis.

${ }^{\mathrm{c}} n=1,148$ due to four missing points 

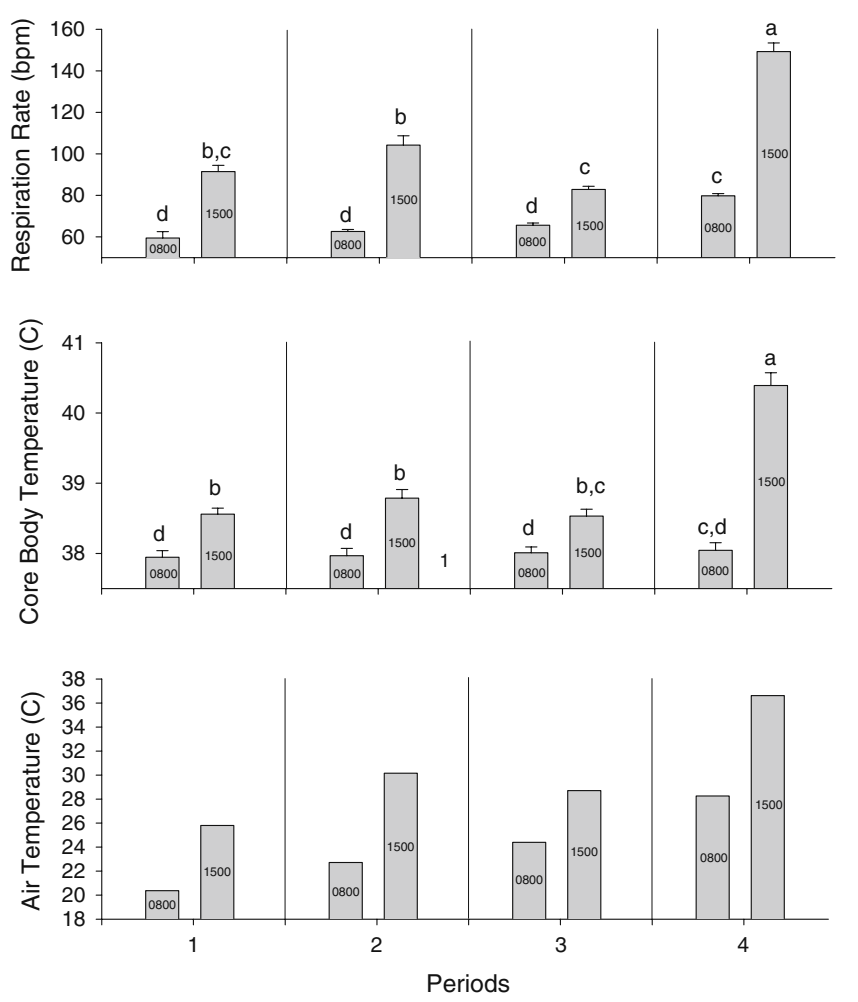

Fig. 6 Average values for respiration rate, core body temperature, and air temperature at 0800 and 1500 hours are shown for each period. Dependent variables with the same letter over the bar are not significantly different within the variable. The vertical line on top of each variable bar is 1 SEM

without changing $R^{2}$ or $\mathrm{C} p$ values. These similarities between the components of models for maximum $\mathrm{RR}$ and $T_{\text {core }}$ were expected after noting the parallel shifts in both variables from 0800 to 1500 hours in all periods (Fig. 6). Ultimately, statistical model \#5 would be the best choice for use in the field environment as it did not require the measurement of $T_{\mathrm{bg}}$ and, as a result, needs measurements of only $T_{\mathrm{a}}$ and $T_{\text {core. }}$.

\section{Discussion}

Several researchers have developed models to predict thermal strain in cattle due to summer heat stress (Howden and Turnpenny 1998; Gaughan et al. 1999; Brown-Brandl et al. 2005b; Mader et al. 2006). Brown-Brandl et al. (2005b) stated that, at minimum, the indicator should utilize a current weather parameter, such as air temperature, percent relative humidity, wind speed, or solar radiation. However, an indicator based on the thermal status of the animal such as respiration rate or body temperature combined with meteorological parameters may serve as an integrated predictor of the animal strain. Many of these models are very complex and require background information about each animal to be accurate.

A second order polynomial regression was used to relate $T_{\mathrm{a}}, T_{\mathrm{bg}}, \mathrm{THI}, \mathrm{BGTHI}$ and $T_{\text {core }}$ in the present study. The relationships with $T_{\mathrm{a}}$ had the greater correlation with $T_{\text {core }}$. This superior relationship is consistent with previous research (Chemineau and Ravault 1984). In a study conducted by Dikmen and Hansen (2009), the authors compared eight different THI equations and other meteorological variables (wind speed, $T_{\mathrm{a}}, \mathrm{RH}$ ) to determine which best predicted rectal temperature of lactating cows. The results demonstrated that $T_{\mathrm{a}}$ was nearly as good a predictor of rectal temperatures of lactating Holsteins as any of the THI equations $\left(R^{2}=0.41\right.$ versus 0.43$)$. Similarly, da Silva et al. (2007), looking at six different indicies, found THI and BGTHI had the lowest correlations with rectal temperature and respiration rate. In Missouri, percent relative humidity is relatively low in comparison to southern United States. For this reason THI, which relies heavily on the humidity component, may not significantly contribute to predictions of thermal stress in this region of the US. Likewise BGTHI, which uses $T_{\mathrm{bg}}$ instead of $T_{\mathrm{a}}$, did not improve the prediction of $T_{\text {core }}$. Chemineau and Ravault
Table 5 Maximum respiration rate (RR) prediction analysis using the average of both days in each period

${ }^{a}$ First combination of four variables to predict maximum RR

${ }^{b}$ First combination of five variables to predict maximum RR

\begin{tabular}{|c|c|c|c|c|c|c|c|c|c|c|c|}
\hline \multirow[b]{2}{*}{ Variable } & \multirow[b]{2}{*}{ Code } & \multicolumn{5}{|c|}{ Four variable comparisons } & \multicolumn{5}{|c|}{ Five variable comparisons } \\
\hline & & $1^{\mathrm{a}}$ & 2 & 3 & 4 & 5 & $6^{\mathrm{b}}$ & 7 & 8 & 9 & 10 \\
\hline Min $\mathrm{T}_{\text {core }}$ & $\mathrm{X}_{1}$ & $\mathrm{X}_{1}$ & $\mathrm{X}_{1}$ & $\mathrm{X}_{1}$ & $\mathrm{X}_{1}$ & $\mathrm{X}_{1}$ & $\mathrm{X}_{1}$ & $X_{1}$ & $\mathrm{X}_{1}$ & $\mathrm{X}_{1}$ & $\mathrm{X}_{1}$ \\
\hline Max $\mathrm{T}_{\text {core }}$ & $\mathrm{X}_{2}$ & & & & & & $\mathrm{X}_{2}$ & $\mathrm{X}_{2}$ & $\mathrm{X}_{2}$ & $\mathrm{X}_{2}$ & $\mathrm{X}_{2}$ \\
\hline Min RR & $\mathrm{X}_{3}$ & & & & & & & & & & \\
\hline $\mathrm{T}_{\mathrm{a}}$ Slope & $\mathrm{X}_{4}$ & $\mathrm{X}_{4}$ & $\mathrm{X}_{4}$ & $\mathrm{X}_{4}$ & $\mathrm{X}_{4}$ & & $\mathrm{X}_{4}$ & $\mathrm{X}_{4}$ & $\mathrm{X}_{4}$ & $\mathrm{X}_{4}$ & \\
\hline BG Slope & $\mathrm{X}_{5}$ & $\mathrm{X}_{5}$ & $\mathrm{X}_{5}$ & $\mathrm{X}_{5}$ & $\mathrm{X}_{5}$ & & $\mathrm{X}_{5}$ & $\mathrm{X}_{5}$ & $\mathrm{X}_{5}$ & $\mathrm{X}_{5}$ & $\mathrm{X}_{5}$ \\
\hline $\operatorname{Min} T_{a}$ & $\mathrm{X}_{6}$ & & $\mathrm{X}_{6}$ & & & $\mathrm{X}_{6}$ & & $\mathrm{X}_{6}$ & & & \\
\hline $\operatorname{Max} \mathrm{T}_{\mathrm{a}}$ & $\mathrm{X}_{7}$ & & & $\mathrm{X}_{7}$ & & & & & $\mathrm{X}_{7}$ & & $\mathrm{X}_{7}$ \\
\hline Min BG & $\mathrm{X}_{8}$ & $\mathrm{X}_{8}$ & & & & $\mathrm{X}_{8}$ & $\mathrm{X}_{8}$ & & & & \\
\hline Max BG & $\mathrm{X}_{9}$ & & & & $\mathrm{X}_{9}$ & $\mathrm{X}_{9}$ & & & & $\mathrm{X}_{9}$ & $\mathrm{X}_{9}$ \\
\hline $\mathrm{R}^{2}$ & & 0.84 & 0.84 & 0.84 & 0.84 & 0.84 & 0.85 & 0.85 & 0.85 & 0.85 & 0.85 \\
\hline $\mathrm{Cp} p$ & & 5.33 & 5.33 & 5.33 & 5.33 & 5.33 & 5.96 & 5.96 & 5.96 & 5.96 & 5.96 \\
\hline
\end{tabular}


Table 6 Maximum $T_{\text {core }}$ prediction analysis using the average of both days in each period

\begin{tabular}{|c|c|c|c|c|c|c|c|c|c|c|c|}
\hline \multirow[b]{2}{*}{ Variable } & \multirow[b]{2}{*}{ Code } & \multirow{2}{*}{$\begin{array}{l}\text { Three variable } \\
\text { comparisons } \\
1^{\mathrm{a}}\end{array}$} & \multicolumn{5}{|c|}{$\begin{array}{l}\text { Four variable } \\
\text { comparisons }\end{array}$} & \multicolumn{4}{|c|}{$\begin{array}{l}\text { Five variable } \\
\text { comparisons }\end{array}$} \\
\hline & & & 2 & 3 & 4 & $5^{\mathrm{b}}$ & $6^{\mathrm{c}}$ & 7 & 8 & 9 & 10 \\
\hline Min $\mathrm{T}_{\text {core }}$ & $\mathrm{X}_{1}$ & $\mathrm{X}_{1}$ & $\mathrm{X}_{1}$ & $\mathrm{X}_{1}$ & $\mathrm{X}_{1}$ & $\mathrm{X}_{1}$ & $\mathrm{X}_{1}$ & $\mathrm{X}_{1}$ & $\mathrm{X}_{1}$ & $\mathrm{X}_{1}$ & $\mathrm{X}_{1}$ \\
\hline Min RR & $\mathrm{X}_{2}$ & & & & & & & & & & \\
\hline Max RR & $\mathrm{X}_{3}$ & & & & & & $\mathrm{X}_{3}$ & $\mathrm{X}_{3}$ & $\mathrm{X}_{3}$ & $\mathrm{X}_{3}$ & $X_{3}$ \\
\hline $\mathrm{T}_{\mathrm{a}}$ Slope & $\mathrm{X}_{4}$ & & $\mathrm{X}_{4}$ & $\mathrm{X}_{4}$ & & $\mathrm{X}_{4}$ & $\mathrm{X}_{4}$ & $\mathrm{X}_{4}$ & $\mathrm{X}_{4}$ & $\mathrm{X}_{4}$ & $\mathrm{X}_{4}$ \\
\hline BG Slope & $\mathrm{X}_{5}$ & & $\mathrm{X}_{5}$ & $\mathrm{X}_{5}$ & $\mathrm{X}_{5}$ & & & $\mathrm{X}_{5}$ & $\mathrm{X}_{5}$ & $\mathrm{X}_{5}$ & \\
\hline $\operatorname{Min} \mathrm{T}_{\mathrm{a}}$ & $\mathrm{X}_{6}$ & $X_{6}$ & & $\mathrm{X}_{6}$ & $\mathrm{X}_{6}$ & $\mathrm{X}_{6}$ & & & & $\mathrm{X}_{6}$ & $\mathrm{X}_{6}$ \\
\hline $\operatorname{Max} T_{a}$ & $\mathrm{X}_{7}$ & $\mathrm{X}_{7}$ & $\mathrm{X}_{7}$ & & & $\mathrm{X}_{7}$ & & & $\mathrm{X}_{7}$ & & \\
\hline Min BG & $\mathrm{X}_{8}$ & & $\mathrm{X}_{8}$ & & $\mathrm{X}_{8}$ & & & $\mathrm{X}_{8}$ & & & $\mathrm{X}_{8}$ \\
\hline Max BG & $\mathrm{X}_{9}$ & & & & & & $\mathrm{X}_{9}$ & & & & \\
\hline $\mathrm{R}^{2}$ & & 0.69 & 0.85 & 0.85 & 0.85 & 0.85 & 0.83 & 0.86 & 0.86 & 0.86 & 0.86 \\
\hline $\mathrm{C} p$ & & 44.60 & 4.61 & 4.61 & 4.61 & 4.61 & 12.44 & 5.26 & 5.26 & 5.26 & 5.26 \\
\hline
\end{tabular}

(1984) determined that overall $T_{\mathrm{a}}$ showed greater correlation with rectal temperature compared to $\mathrm{T}_{\mathrm{bg}}$; however, the two variables exhibited similar correlations during the summer. In the present study, $T_{\mathrm{a}}$ and $T_{\mathrm{bg}}$ separated above a critical environmental temperature of $25^{\circ} \mathrm{C}$ due to a lag in the $T_{\text {core }}$ response (Fig. 4). This lag in the $T_{\mathrm{bg}}$ response compared to $T_{\mathrm{a}}$ is due to the rapid rate of rise in $T_{\mathrm{bg}}$ throughout the day, which continues for a longer period than for $\mathrm{T}_{\mathrm{a}}$ (Fig. 1). The $T_{\mathrm{bg}}$ value combines the influence of $T_{\mathrm{a}}$, air movement and radiant heat load (Bond and Kelly 1955), and has often been used as a general model for animals for the exchange with the environment. Gaughan et al. (2008) also considered it to be important as it is included in a new Heat Load Index for beef cattle together with relative humidity and wind speed to predict panting score.

The critical point for $T_{\mathrm{a}}$-induced increase in $T_{\text {core }}$ in the present study was approximately $25^{\circ} \mathrm{C}$. Others have reported a similar critical $T_{\mathrm{a}}$ (Hahn et al. 1992; Lefcourt and Adams 1996; Leonard et al. 2001). In some cases, the studies were performed in environmental chambers (Hahn et al. 1992; Leonard et al. 2001) without the impact of solar radiation. Hahn et al. (1992), using fractal analysis, determined that the threshold $T_{\mathrm{a}}$ was $25^{\circ} \mathrm{C}$ for growing cattle. Leonard et al. (2001), using break-point analysis, derived a similar $T_{\mathrm{a}}$ threshold between 24.8 and $25.1^{\circ} \mathrm{C}$. Lefcourt and Adams (1996) found that the threshold for the increase in $T_{\text {core }}$ was $25.6^{\circ} \mathrm{C}$. This latter study, like the present one, was run in unshaded feedlots. It is interesting to note that, regardless of the presence of solar radiation, the threshold $T_{\mathrm{a}}$ were very similar. This $T_{\mathrm{a}}$ level appears to be very important and warrants further study as it has also been reported to be the threshold $T_{\mathrm{a}}$ for a decline in feed intake (Hahn 1999) and an increase in sweating rate (McLean 1963).
Minimum daily $T_{\text {core }}$ in the present study usually occurred during morning (0500-0700 hours), and were consistent with the daily minimum $T_{\mathrm{a}}$ (0700-0800 hours). However, despite relatively large differences in morning $T_{\mathrm{a}}$ (Fig. 2), animals were able to bring minimum $T_{\text {core }}$ to a similar level during each morning period after nighttime recovery. The increase in core-to-ambient thermal gradient at night enhanced heat dissipation and resulted in a rapid reduction in $T_{\text {core }}$ regardless of the daytime high $T_{\mathrm{a}}$. This phenomenon, known as nighttime cooling, has been documented by many others (Scott et al. 1983; Igono et al. 1992; Blackshaw and Blackshaw 1994; Mader et al. 2006; Gaughan et al. 2008), and is becoming exceedingly important as research continues to show that nighttime low $T_{\mathrm{a}}$ appears to be just as important as daytime high $T_{\mathrm{a}}$ in determining heat stress response (Mader et al. 2006). It is also believed that the nighttime recovery period is an essential element for survival during severe heat waves (Nienaber and Hahn 2007). Igono et al. (1992) found that the cool portions of the day (below $21^{\circ} \mathrm{C}$ ) provided a margin of safety for reducing the effects of heat stress on production. In the present study, animals were housed in unshaded feedlots allowing them to easily radiate heat to the night sky and surroundings. This nighttime cooling allowed steers to minimize the effects of the changing daytime heat stress conditions.

One of the major objectives for this paper was to determine an adequate predictor of stress. The first step in accomplishing this was to determine the relationship between thermal status of the animal and the environment thermal stress. Thermal status is often assessed using physiological parameters such as RR or $T_{\text {core }}$. McDoweIl (1972) found that increased $R R$ is the first outward indication that a cow is responding to increased thermal load. This is expected as increased RR is one of several 
heat loss mechanisms that precede a change in $T_{\text {core }}$ to effectively maintain normal heat balance. Gaalaas (1945) reported that variability of RR increases sharply as $T_{\mathrm{a}}$ rises above $21{ }^{\circ} \mathrm{C}$. Likewise, Hahn et al. (1997) found the threshold for respiration rate to be $21.3^{\circ} \mathrm{C}$. This is much lower than the threshold of $24-25^{\circ} \mathrm{C}$ for increased core body temperature and decreased feed intake (Hahn et al. 1992). Likewise, RR is more readily observable in the field than many indicators of stress such as core body temperature. Respiration rate also shows a good repeatability during successive heat exposures.

Previous research has suggested that RR may not be a good measure for discriminating differences in thermal status among individuals (Bianca 1963; Hahn et al. 1997). Bianca (1963), while examining individual animal variation, found that some animals tended to have consistently higher or lower RR than others at all $T_{\mathrm{a}}$. Hahn et al. (1997) reported similar findings also showing that the $T_{\mathrm{a}}$ threshold for increases in RR varies across individuals $\left(17^{\circ} \mathrm{C}\right.$ to $\left.23^{\circ} \mathrm{C}\right)$. In the present study, individual animals were ranked based on minimum and maximum $T_{\text {core }}$ to look at animal variation. Similarly to RR, these rankings showed that some animals maintained a lower $T_{\text {core }}$ regardless of $T_{\mathrm{a}}$ (Fig. 7). These rankings were remarkably consistent across period in terms of minimum $T_{\text {core, }}$ but not maximum $T_{\text {core }}$ (Fig. 7). It is interesting to note that while RR has a higher repeatability and similar individual animal variation than $T_{\text {core }}$, stepwise regression results showed that $\mathrm{RR}$ at 0800 was not a necessary component to predict maximum $T_{\text {core }}$ or $\mathrm{RR}$ at 1500.

One component present in other predictive models is a lag in the $T_{\text {core }}$ response to $T_{\mathrm{a}}$. This lag behind $T_{\mathrm{a}}$ is attributed to the thermal inertia associated with the large body size of cattle (Scott et al. 1983; Hahn 1989; Hahn 1999; Mader 2003; Parkhurst 2010). However, data from these studies are inconsistent, showing that $T_{\text {core }}$ can lag behind $T_{\mathrm{a}}$ from 1 to $5 \mathrm{~h}$, and is highly dependent on ambient conditions. In the present study, the analysis of a $T_{\text {core }}$ lag yielded no benefit to $T_{\mathrm{a}}$ correlations (Table 4), and was left out of the analysis to create the simplest model. In contrast, $T_{\mathrm{bg}}$, which had a greater rate of rise compared to $T_{\mathrm{a}}$, did increase the correlation coefficient when a lag effect was tested (Table 4). There are several possible explanations for the diminished lag response in the current study. The lack of a delay effect is likely due to the greater and more rapid impact of direct solar radiation on the heating process compared to indirect heating within shaded or indoor facilities. In addition, the daily increase in thermal stress may not have been of sufficient magnitude, especially with the nighttime low around $25^{\circ} \mathrm{C}$, to elicit the pronounced lag seen in other studies (Hahn 1989; Mader 2003; Parkhurst 2010). Another reason for the difference in this study is possibly the location of the telemetric transmitter in
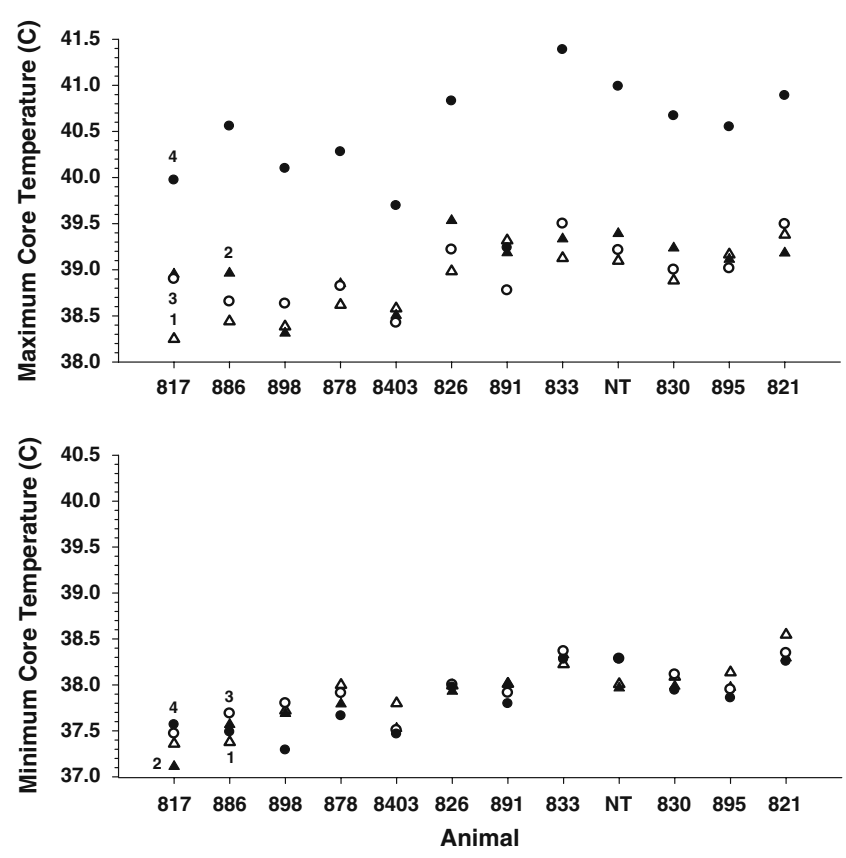

Fig. 7 Maximum and minimum core body temperature values for each animal in each period is shown. Periods are indicated by numbers near the start of each line

the body. Several studies have demonstrated that while many sites used for body temperature measurement (i.e., tympanic, rectal, vaginal, sub-dermal, and ruminal) are correlated with each other, some areas are more reflective of changes in the external environment (Guidry and McDowell 1966; Seawright et al. 1984; Hahn et al. 1990). Hahn et al. (1990), in a controlled chamber study, found that subdermal sites were influenced rapidly by environmental stimuli, while tympanic remained fairly constant. Rectal temperature, under the same conditions, was the most constant and the last temperature to change with ambient. Similarly, Seawright et al. (1984) showed that subdermal temperatures reflected the dynamic ambient environments more than core body temperature response sites in humans. In the current study, telemetric transmitters were surgically implanted into the abdominal cavity of the animal, which may better reflect core body temperature changes to external stimuli (Hahn et al. 1990).

Many independent ambient variables have been used to predict rectal temperature for cattle (Brown-Brandl et al. 2005a). Kabuga (1992) found that minimum and maximum air temperature on the previous day, combined with the current day, yielded a good correlation to peak rectal temperature. Others use THI, respiration rate, and average air temperature (Ingraham et al. 1979). While these measures do yield a high correlation with rectal temperature, many of the variables used require computers to forecast weather data to plug into the model (Eigenberg et al. 2003). Although many ambient variables were 
correlated with $T_{\text {core }}$ in the present study, minimum $T_{\text {core }}$ proved to be the necessary component to predict maximum $T_{\text {core }}$. However, measurement of $T_{\text {core }}$ presents a problem, as it is often difficult to obtain continuously. Though this is not a new technology (Bligh and Robinson 1963), it has taken some time for the application of continuous measurements to catch up. Continuous measurement systems are relatively expensive and may require time consuming calibrations, but should become less of an issue as telemetric transmitters become widely available. Another component in the regression analysis was $T_{\mathrm{a}}$ slope from 0600 to 0800 hours. The slope indicates how fast the temperature is changing over this 2 -h period, and is a reliable determinant of the level of thermal stress for the entire day assuming a normal $T_{\mathrm{a}}$ trajectory. Rate of change in ambient conditions has not been extensively studied in correlation with $T_{\text {core }}$, but is known to be important in other physiological systems (i.e., thermoreceptors in the skin sense rate of temperature change causing an increase in neuron firing rate; Wurster and McCook 1969). Many researchers (Gaalaas 1945; Kabuga 1992; Arias and Mader 2009) measure this change from minimum to maximum daily levels but have not accounted for the importance of the initial rise and the differing rates throughout the day.

One of the objectives of this study was to determine the minimal set of observations needed to identify peak daily thermal strain (Fig. 5a). Segments of the daily $T_{\text {core }}$ relationship to $T_{\mathrm{a}}$ were compared using animals in the four periods to determine which produces the greatest $R^{2}$ using a quadratic relationship (Fig. 4). Segments included "All Hours", the daily rise in $T_{\text {a }}$ (i.e., 0700 to 1600 ) and only 0800 and 1500 . The last segment was to correspond with the measurement times for RR. These results demonstrate that during a moderate to significant heat stress (i.e., the largest daily increase in $T_{\text {core }}$ ), a measurement of $T_{\text {core }}$ at only the lowest (i.e., 0800) and highest (i.e., 1500) air temperatures of day are sufficient to predict heat strain that is comparable to using all hours of the day. This has important implications for producers, suggesting it may not be necessary to purchase expensive telemetric transmitter systems to continuously monitor animals.

The goal of any predictive model is to predict as accurately as possible a given response with the lowest number of variables. That said, there are two major issues in developing predictive models for predicting animal responses to air temperature. The first issue is correlating some measurable parameter (i.e., $T_{\text {core }}, \mathrm{RR}$, skin temperature, etc.) to the thermal status of the animal. The present study has identified minimum $T_{\text {core }}$ as a necessary component to predict the thermal status of the animal. The second and largest issue is the reliance on meteorological variables. These values such as air temperature, relative humidity, radiation, and wind speed have all been used in prediction models. However, these values are determined from meteorological and computer forecast models with a large error rate (Orrell et al. 2001) comparable to that of the scientist trying to predict the thermal status of the animal. The goal of this paper was not to develop a model for prediction, but to identify variables that may be important for development of models. The present study under moderately stressing summer conditions found that a rise in air temperature and black globe between 0600 and 0800 (measured in slope) are important components to predict thermal status. Minimum and maximum temperatures were also components used in the stepwise regression, but as stated above, minimum $T_{\text {core }}$ is the determining factor for having an accurate prediction.

Acknowledgments This material is based upon work supported by the US Department of Agriculture (USDA/NRI competitive grant \#980352 S). Any opinions, findings, conclusion, or recommendations expressed in this publication are those of the author(s) and do not necessarily reflect the view of the US Department of Agriculture.

\section{References}

Arias R, Mader TL (2009) Effects of environmental factors on body temperature of feedlot cattle. In: Nebraska Beef Report, Department of Animal Science, University of Nebraska, Lincoln, pp 102-104

Bayarri S, Durán L, Costell E (2003) Compression resistance, sweetener's diffusion and sweetness of hydrocolloids gels. Int Dairy J 13:643-653

Bianca W (1963) Rectal temperature and respiratory rate as indicators of heat tolerance in cattle. J Agric Sci 60:113-118

Blackshaw JK, Blackshaw AW (1994) Heat stress in cattle and the effect of shade on production and behaviour: a review. Aust J Exp Agric 34:285-295

Bligh J, Robinson SG (1963) Continuous telemetry of the deep body temperature of sheep under field conditions. J Physiol 165:1P

Bond TE, Kelly CF (1955) The globe thermometer in agricultural research. Agric Eng 36:251-260

Brown-Brandl TM, Eigenberg RA, Nienaber JA, Hahn GL (2005a) Dynamic response indicators of heat stress in shaded and nonshaded feedlot cattle, Part 1: analysis of indicators. Biosyst Eng 90:451-462

Brown-Brandl TM, Jones DD, Woldt WE (2005b) Evaluating modeling techniques for cattle heat stress prediction. Biosyst Eng 91:513-524

Buffington DE, Collazo-Arocho A, Canton GH, Pitt D, Thatcher WW, Collier RJ (1981) Black globe-humidity index (BGHI) as comfort equation for dairy cows. Trans ASAE 24:711-714

Chemineau P, Ravault JP (1984) Variations horaires de la température rectale et de la prolactinémie chez le Cabrit créole maintenu à l'extérieur en milieu tropical (in French, with English summary). Reprod Nutr Dev 24:71-80

Collier RJ, Zimbelman RB (2007) Heat stress effects on cattle: What we know and what we don't know. In: Proceedings of the 22nd Annual Southwest Nutrition and Management Conference. Tempe, AZ, pp 76-83

da Silva RG, Morais DAEF, Guilhermino MM (2007) Evaluation of thermal stress indexes for dairy cows in tropical regions. Rev Bras Zootecnia 36:1192-1198 
Dikmen S, Hansen PJ (2009) Is the temperature-humidity index the best indicator of heat stress in lactating dairy cows in a subtropical environment? J Dairy Sci 92:109-116

Eigenberg RA, Brown-Brandl TM, Nienaber JA (2003) Development of a livestock safety monitor for cattle. ASAE Paper No. 032338, St Joseph, MI

Eigenberg RA, Brown-Brandl TM, Nienaber JA, Hahn GL (2005) Dynamic response indicators of heat stress in shaded and nonshaded feedlot cattle, Part 2: predictive relationships. Biosyst Eng 91:111-118

Fuquay JW (1981) Heat stress as it affects animal production. J Anim Sci 52:164-174

Gaalaas RF (1945) Effect of atmospheric temperature on body temperature and respiration rate of jersey cattle. J Dairy Sci 28:555-563

Gaughan JB, Mader TL, Holt SM, Josey MJ, Rowan K (1999) Heat tolerance of Boran and Tuli crossbred steers. J Anim Sci 77:2398-2405

Gaughan JB, Mader TL, Holt SM (2008) Cooling and feeding strategies to reduce heat load of grain-fed beef cattle in intensive housing. Livestock Sci 113:226-233

Guidry AJ, McDowell RE (1966) Tympanic membrane temperature for indicating rapid changes in body temperature. J Dairy Sci 49:74-77

Hahn GL (1989) Body temperature rhythms in farm animals-a review and reassessment relative to environmental influences. In: Proceedings of the 11th International Society of Biometeorology Congress. SPB, The Hague, The Netherlands, pp 325-337

Hahn GL (1999) Dynamic responses of cattle to thermal heat loads. J Anim Sci 77:10-21

Hahn GL, Eigenberg RA, Nienaber JA, Littledike ET (1990) Measuring physiological responses of animals to environmental stressors using a microcomputer-based portable datalogger. J Anim Sci 68:2658-2665

Hahn GL, Chen YR, Nienaber JA, Eigenberg RA, Parkhurst AM (1992) Characterizing animal stress through fractal analysis of thermoregulatory responses. J Therm Biol 17:115-120

Hahn GL, Parkhurst AM, Gaughan JB (1997) Cattle respiration rate as a function of ambient temperature. ASAE Paper NMC97 121. American Society of Agricultural Engineers, St. Joseph, MO

Hammel HT (1968) Regulation of internal body temperature. Annu Rev Physiol 30:641-710

Howden SM, Turnpenny J (1998) Modeling heat stress and water loss of beef cattle in subtropical Queensland under current climates and climate change. In: International Congress on Modeling and Simulation. Modeling and Simulation Society of Australia, Hobart, Tasmania, pp 1103-1108

Igono MO, Bjotvedt G, Sanford-Crane HT (1992) Environmental profile and critical temperature effects on milk production of Holstein cows in desert climate. Int J Biometeorol 36:77-87

Ingraham RH, Stanley RW, Wagner WC (1979) Seasonal effects of tropical climate on shaded and nonshaded cows as measured by rectal temperature, adrenal cortex hormones, thyroid hormone, and milk production. Am J Vet Res 40:1792-1797
Kabuga JD (1992) The influence of thermal conditions on rectal temperature, respiration rate and pulse rate of lactating HolsteinFriesian cows in the humid tropics. Int J Biometeorol 36:146150

Lefcourt AM, Adams WR (1996) Radiotelemetry measurements of body temperatures of feedlot steers during summer. J Anim Sci 74:2633-2640

Leonard MJ, Spiers DE, Hahn GL (2001) Adaptation of feedlot cattle to repeated sinusoidal heat challenge. In: Proceedings of 6th International Livestock Environment. Trans ASAE, St Joseph, MI, pp 119-128

Mader TL (2003) Environmental stress in confined beef cattle. J Anim Sci 81(E. suppl 2):110-119

Mader TL, Kreikemeier WM (2006) Effects of growth-promoting agents and season on blood metabolites and body temperature in heifers. J Anim Sci 84:1030-1037

Mader TL, Davis MS, Brown-Brand TM (2006) Environmental factors influencing heat stress in feedlot cattle. J Anim Sci $84: 712-719$

Mallows CL (1973) Some comments on Cp. Technometrics 15:661676

McDowell RE (1972) Improvement of livestock production in warm climates. Freeman, San Francisco

McLean JA (1963) The regional distribution of cutaneous moisture vaporization in the Ayrshire calf. J Agric Sci Camb 61:275-280

Nienaber JA, Hahn GL (2007) Livestock production system management responses to thermal challenges. Int J Biometeorol 52:140 157

Orrell D, Smith L, Barkmeijer J, Palmer TN (2001) Model error in weather forecasting. Nonlin Proc Geophys 8:357-371

Parkhurst AM (2010) Model for understanding thermal hysteresis during heat stress: a matter of direction. Intl J Biometeorol. Epub ahead of print, doi:10.1007/s00484-009-0299-Z

Scott IM, Johnson HD, Hahn GL (1983) Effect of programmed diurnal temperature cycles on plasma thyroxine level, body temperature, and feed intake of Holstein dairy cows. Int $\mathrm{J}$ Biometeorol 27:47-62

Seawright GL, Brown RR, Campbell K, Levings RL, Araki CT (1984) Comparison of remotely acquired deep body and subdermal temperature measurements for detecting fever in cattle. In: Agricultural Electronics in 1983 and Beyond. AMSAE, St. Joseph, MI, pp 517-528

Silanikove N (2000) Effects of heat stress on the welfare of extensively managed domestic ruminants. Livest Prod Sci 67:118

Thom EC (1959) The discomfort index. Weatherwise 12:57-59

Wurster RD, McCook RD (1969) Influence of rate of change in skin temperature on sweating. J Appl Physiol 27:237-240

Yousef MK (1989) Importance of field studies in stress physiology. In: Anderson DM, Havstad M, Hinds FL (eds) Stress and the free ranging animal. New Mexico State University, Agricultural Experimental Station Research Report 646, pp 15-30 